\title{
Drawn from Memory: reminiscing, narrative and the visual image
}

\author{
Terence Wright \\ University of Ulster \\ York Street \\ Belfast BT15 1ED \\ +44 (0)2890267320 \\ t.wright@ulster.ac.uk
}

\begin{abstract}
A brief review of Marcel Proust's views on art, photography and memory, as expressed in his $\dot{A}$ la recherche $d u$ temps perdu (1913-27), sets the scene for a discussion of the value of photographs as triggers for reminiscing as well as scope and limitations for computer-based visual narratives. The paper is illustrated by three short video interviews with inhabitants of the Czech Republic and the Republic of Ireland. Each clip was shot as part of interactive flexible narrative programmes: "NM2: New Media for a New Millennium" a practice-based research project partially funded by the EC or a FUSION cross-border creative and digital media economic development project, funded as part of the Northern Ireland Peace Process. The clips demonstrate a range of different approaches to reminiscing. They include personal reminisces, social memory and a diachronic method of relating the past. The interviews form the basis for a discussion about the role of the visual image serving as a stimulus for reminiscing. For example we shall consider how personal memory relates to cultural memory, how the 'objects of memory' can be drawn upon and how they are recounted. Thus the function of photographicbased images as memory aids, or as stimuli for reminiscing, is placed in the context of the narratives that can be constructed around the image. The paper questions the role that photographic images have in the formation and reinforcement of personal and social identity. In such cases memory does not necessarily need to be based on events that have been directly experienced.
\end{abstract}

\section{Keywords}

Interactive documentary; Proust; memory; photography; narrative; photo-elicitation; Interactive Village; Czech Republic.

\section{INTRODUCTION}

In his $A$ la recherche du temps perdu (usually translated as In Search of Lost Time or Remembrance of Things Past), the aroma exuded by a madeleine (a small cake) when dipped into tea takes Marcel Proust's (semi-autobiographical) narrator back to thoughts and memories of his early childhood [1]. This well-known episode has almost become something of a cliché in studies of literature and is often cited as a popular reference to reminiscing. Nevertheless, Proust's Madeleine not only forms a literary landmark, but would appear to be a natural starting point for anyone interested in the narration of memory in the modern era. Although the 'casual reader' might assume that $A$ la recherche $d u$ temps perdu "consists of nothing more than page upon page of recollected details ... Proust does more than just recount his past, he also observes his memory in action, and uses these observations to develop a comprehensive theory of conscious experience and artistic creation that potentially has profound implications for any scientific theory of consciousness" (Epstein 2004:214)

Proust's recollections are presented in a self-reflexive mode of narration which allows him to examine and evaluate his own processes of writing. So while the madeleine episode provides a famous example of how a simple everyday act can trigger a train of reminiscences of former times, the novel traces the author's growing realisation of the value of recording his memories in literary form - in fact, as readers, we come to realise that the very book that we are reading is the product of these musings. Yet further, according to Proust, everyone is capable of producing art that functions by communicating our life experiences and making them understandable to others. As Epstein (2004: 213) elaborates "Proust argues that the function of art is to evoke the underlying associative network indirectly in the mind of the observer by using carefully chosen sensory surfaces to control the stream of thought." [2] Proust himself cites examples from the visual arts, literature and music in order to demonstrate that art is inextricably linked to memory and experience. [3] [4] Thus $\dot{A}$ la recherche $d u$ temps perdu furnishes the author with the opportunity to expound his own aesthetic theories through his literary characterisation.

Given Proust's interest in memory, one would naturally expect that photographs would play an important role in serving as 'triggers' for reminiscing. However, according to Susan Sontag, Proust's aesthetics did not extend to the realm of lens-based media: 
"Whenever Proust mentions photographs, he does so disparagingly: as a synonym for a shallow, too exclusively visual, merely voluntary relation to the past, whose yield is insignificant compared with the deep discoveries to be made by responding to cues given by all the senses - the technique he called 'involuntary memory'." [5]

In contrast Brassaï, in his study Proust in the Power of Photography, makes a convincing case for photographs and Proust's knowledge of photography as forming a major influence upon his literary style as well as serving a personal need: "my memory ... has such lapses that photographs are very precious to me. I keep them as a sort of reinforcement and do not look at them too often in order not to exhaust their powers" [6]

Certainly, Proust's regard for photography and film might appear somewhat contradictory. This leads Danius (2002: 119) to conclude: "the narrator needs photography for his theory of memory; photography is mobilized precisely for us to understand the true nature of memory - by way of that which it is not. The same is true of cinematography; it, too, is posited as alien to mnemonic processes." [7]

Naturally Proust's "madeleine effect" constitutes part of the reading process. "Just as the taste and smell of a piece of madeleine dipped into a cup of tea took Marcel Proust back to the village of his childhood, a single word, a name, or an image is often all the reader needs to be transported into a cherished landscape - or into an initially hated one that grew close to the heart with the passing of time" [8] And although Proust himself maintains that "Nothing is further from what we have really perceived than the vision that cinematography presents" (Danius p. 119), a type of 'madeleine device' has entered the cinematic narrative. For instance, in the opening scenes of Victor Erice's El Sur[9] Estrella (the young protagonist) removes the lid from a small black box and draws out a small chain and pendulum that belonged to her father. For her this action constitutes a 'madeleine moment'; for the viewer, it is a precursory metaphor: opening and unthreading the narrative chain of Estrella's story which we are about to witness on screen. This kind of 'embedded' narrative device has become a common feature of modern literature and has specific relevance to the Irish style of storytelling "The closed book is opened; something potent enough to keep under lock and key is released. It is a recurring motif in nineteenth century historical novels, and closely related to the Irish approach to narrative" [10] (Foster 2001:3)

Danius (echoing Brassaï: an eminent photographer) maintains that "photographic modes of representation are fundamental to the success of Proust's visual aesthetics." (p. 94) yet furthermore "the narrator alludes to the emergent crisis of art triggered by the advent of new media" (p. 121). Thus, we find in $\dot{A}$ la recherche $d u$ temps perdu, the recurring interlinked themes of memory and reminiscence, theories of art, self-reflexive narrativity, lens-based media and a coming to terms with new technology. In our present era (ninety years or so after the publication of the novel) many of the issues raised by Proust remain specially relevant to the field of interactive storytelling and the visualisation of memory.

\section{THE INTERACTIVE VILLAGE}

"The computer can be used to extend or demolish traditional narrative concepts in all sorts of ways, but its ability to combine narration and simulation has been particularly significant in digital art, electronic literature, and video games" Montfort 2007: 172 [11]

With this type of sentiment in mind, The Interactive Village: a prototype production using interactive multimedia tools, was developed as part of the European research project NM2 (New Media for a New Millennium). [12] The production, which offers a documentary profile of the Czech village Dolní Roveň, allows users to piece together an individual viewing narrative based on their own interests and choices. These can be selected through interaction with the user interface, which facilitates navigation through the village to meet the inhabitants and to determine subject and depth of the information. As such the project can be seen to echo Proust's notions of communicating life experiences to make them understandable to others, as well as experimenting with new modes of visual representation and storytelling afforded by new technologies.

The documentary approach taken in Interactive Village is based on the belief that the 'documentary' genre can "give voice to those, generally outside established elites, who were able to speak to the nature of daily life in a particularly compelling manner" [13] intends to address "human interest" stories. Its purpose is not to offer a programme formula as such, rather to test out a variety of strategies that could be easily adapted to future programming scenarios.[14] One such scenario (currently under discussion) is that of enabling older people to use interactive technologies for the purpose of reminiscing.

We (the producers) had visited the village on a regular basis over a period of 2 years and worked in close collaboration with anthropologists from the University of Pardubice in order to identify and collect relevant information. This included shooting of video material, establishing shots, archive images (still photographs and, in some instances, paintings made by local children), video diaries and cut-away details. It was always evident that its significance would not be fully realised without allowing the user to navigate in the village. This not only mirrored the exploratory nature of the filming process, but developed a virtual landscape in which the viewer could explore the village. In the gathering of material for the production, rather than shooting a definitive storyline (or storylines), we found ourselves looking for "narrative potentials" in the style of the early stages of investigative journalism - bearing in mind it is a 'story' that does not have to be finally "written-up" in a definitive manner. Consequently it is up to the users to develop the narrative building blocks provided by the media tools into the "story" of their own choice. The "shapeshift" production tools, developed by the NM2 project, provided the ideal environment for making such a usernavigable production. [15] To cite one example, viewers can choose the character who narrates the ethnography. They can opt for an 'unofficial' view of the village from $\mathrm{Mr}$ Zevl, the newsagent or the 'official' view of the mayor, Mrs Vinarova. However the users may prefer the expert 'outsider's' view and select anthropologist Peter Skalník who comments on recent social and political change. Or, yet another view of the village can be selected, perhaps from a female anthropologist. In this case, Hana Novotná can present a different perspective and considers the central role of $\mathrm{Mr} \mathrm{Zevl}$ in the village community.

The Interactive Village production offers a new kind of formula to existing documentary genres, offering a range of unique interactive experiences on a sliding scale from news headline 
presentation to in-depth documentary or from automatic presentation to user-explored/contributed ethnography. Each configuration provides a personalised interactive experience, where the source sequences are configured seamlessly in real time to suit the personal wishes and needs of engagers.

Had money and time permitted, a further development of The Interactive Village would have included a facility for villagers adding their own video diaries so that they could create and access family and local histories. Although we were unable to realise this facility in practice, the potential for personalized reminiscences can be found in the interviews with $\mathrm{Mr}$ Vobratilek, the chief fireman, of the Litetiny fire brigade and $\mathrm{Mr} \mathrm{Zevl}$, the village newsagent.

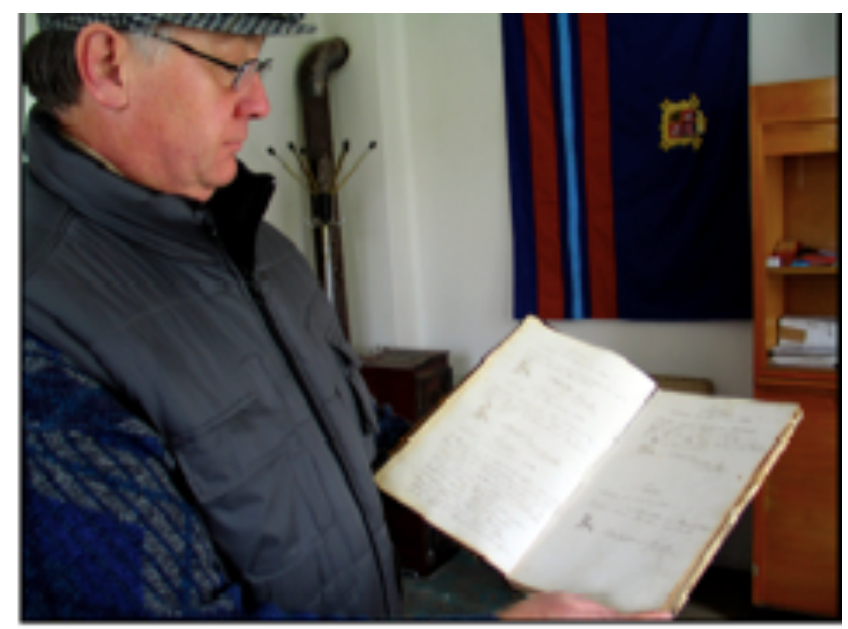

Figure 1 Mr. Vobratilek Litetiny Fire Brigade

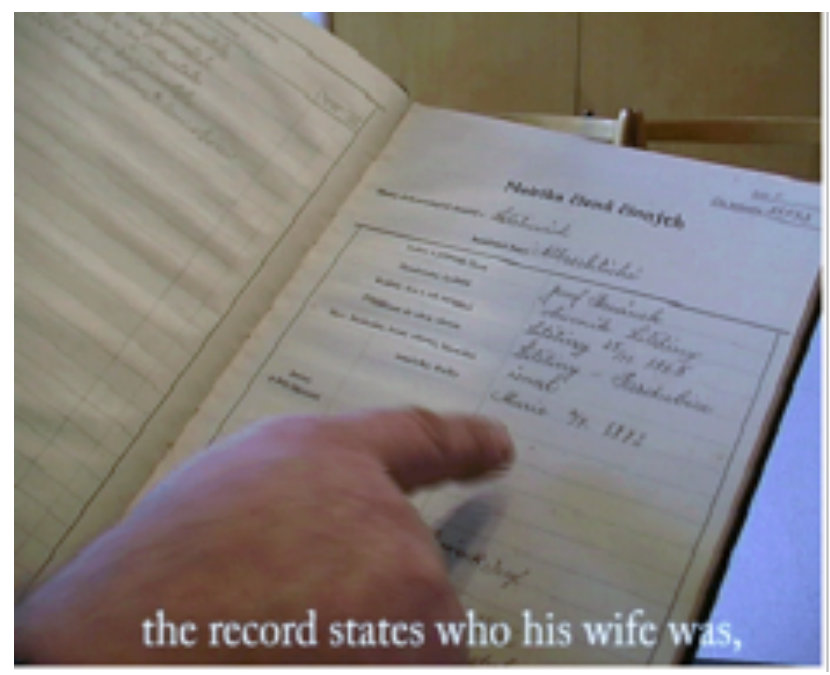

Figure 2 Mr. Vobratilek Use of 'official' records

Not only does Vobratilek's interview show the importance of records and memorabilia in his acts of reminiscing, but also a sense of nostalgia for earlier eras. He hints at a kind of nostalgia for periods of Czech domination by the Austro-Hungarian Empire as well as that of the Communist period when traditions were maintained and life was considered to be better ordered. [16] In this case the "stimulating objects" were not called for by the researchers but were volunteered and sought out by the interviewee. (see Geffroy next section).

One of the advantages of a sustained study, as opposed to the documentary 'snapshot' of the synchronic approach, is that change can be documented as it happens. Besides major structural changes (as the ongoing road improvements that took place throughout the village during the process of the filming), personal changes occurred in the lives of individuals. In the case of $\mathrm{Mr}$. Zevl, the village newsagent, when filming started in 2003, he ran a thriving business that not only proved a viable commercial enterprise, but was the unofficial centre of the village. Situated next to the railway station, it fulfilled a vital social role attracting daily visits from most of the village characters and the gossip that accompanied them.

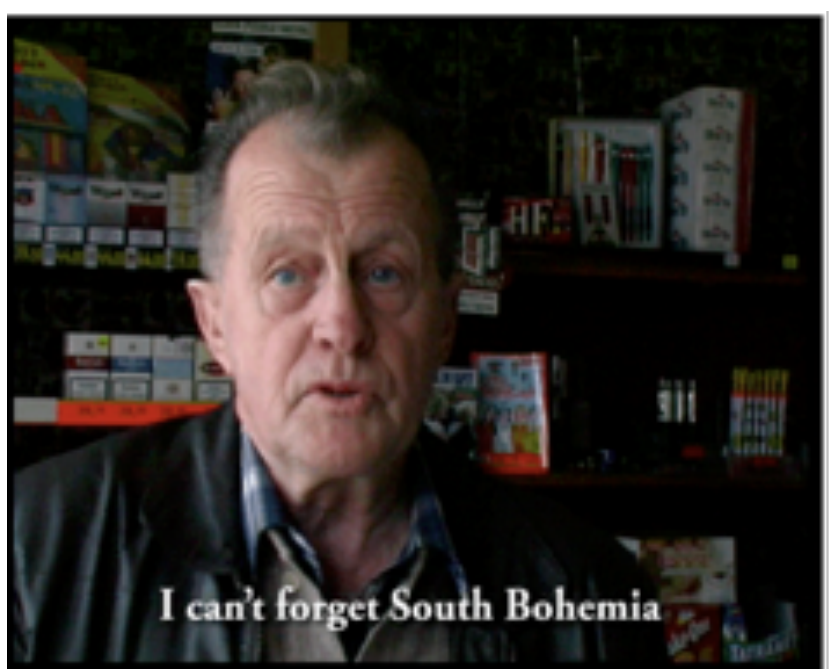

Figure 3 Mr Zevl, newsagent, 2004

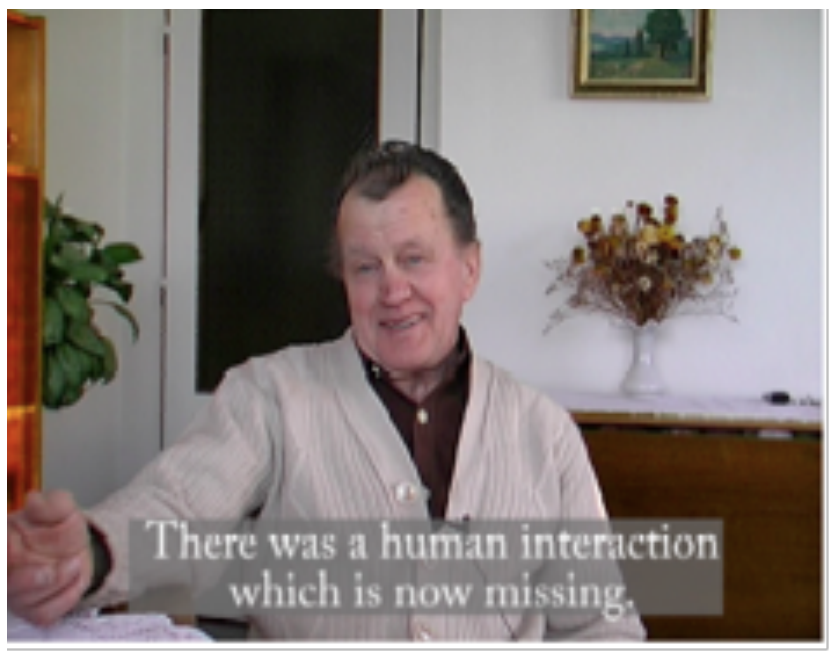

Figure 4 Mr Zevl interviewed 2007

Towards the conclusion of the NM2 research project, Mr. Zevl had given up the business. He was interviewed again in 2007 which gave him the opportunity to reflect on the changes in his life, reminisce on times passed and explain the reasons for his decision to quit. A man well into his 70 s, he admitted "I was 
simply exhausted ... owing to my state of health, it wasn't good". Having already seen himself on screen describing an earlier period of his life provided the context and structure for his narrative. More controversially, his acquired knowledge of the editing style may have influenced the way he tells the story and his delivery through an (unconscious) wish to conform to the perceived format of the production. Nonetheless the combined interviews do provide a useful basis for self-reflexive narratives that can invite the participation of the interviewee as eliciting the contribution of others. In this context, the closure of small businesses run by the recently retired may be a common European experience with significant personal and social implications.

\section{ELICITATION}

"On the surface, photo-elicitation is a straightforward method to understand and utilize. It involves using photographs to invoke comments, memory and discussion in the course of a semistructured interview.” Marcus Banks [17]

Naturally, photography and film have undergone dramatic technological and social changes over the 100 years or so since Proust's era. And despite his position that "photography and film are ... deficient techniques for mnemonic storage and visual mimesis" (Danius p. 118), the anthropologist Marcus Banks points out the value in using photographs and film footage in stimulating memory. He suggests there is an added benefit in that the visual image deflects attention way from the interviewee, perhaps making him or her more comfortable and relaxed by not feeling to be the centre of attention. Geffroy, takes this a step further and cites an example where the interviewers deflection of attention to photographs led his subject to 'volunteer' visual images "She went and opened the doors of an old wall cupboard from which she brought out a large cardboard box, full of photographs, old photographs" p. 374 [18]

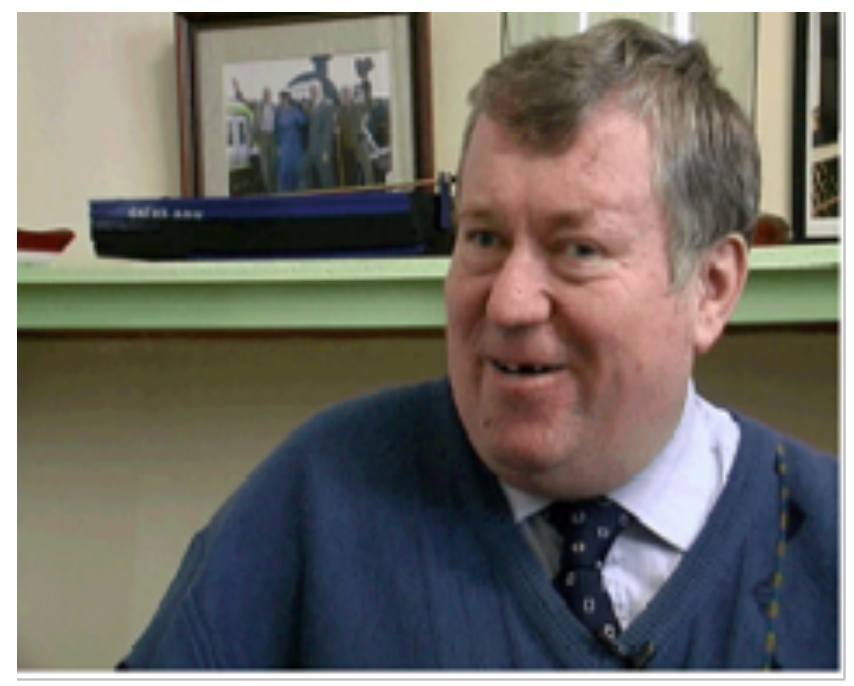

Figure 5 Liam Reilly “There's a story ... I'm not sure if it's true or not, but several people have told me ..."

Similarly historians have found great value in the use of photographs and film to stimulate memory, but may remain skeptical about the reliability of the memories they evoke. Memories are notoriously unreliable in trying to establish the facts, so they need to be checked against other sources. This is apparent in Liam Reilly's account of some of the "myths" surrounding the history of the Drogheda railway viaduct (Fig. 5).

Thus the historian, in her concern for what actually happened, may be concerned with taking a 'forensic' approach to the photograph - different to that of the anthropologist who may be interested in how the present-day subject thinks about the past. In such instances inaccuracies and embellishments may be especially relevant. As an example of the historian's unease, Jordanova (p. 93) expresses her doubts regarding the 'documentary' nature of Walker Evans's photographs of the American Depression of the 1930s "given that they are intensely personal, what generalised insights can be derived from them is unclear. And yet they do convey something extremely significant at an emotional level, so much so that 'the depression' and some kinds of documentary photography have become virtually synonymous." Buteven for the historian there is value in this stirring of emotions "Interviews often pick up dimensions of the past, the way people felt, which are not dependent on the literal exactitude of their memories" Jordanova 124. Jordanova continues by citing the "mêlée" surrounding the troubled relationship between memories and the history of the Holocaust: "there are a number of conflicting perspectives, and the conflicts are not only about what did or did not happen, but how such events should be written about, who has the right to do so, whether historians should assign blame, and so on" (Jordanova p. 125)

However, in the context of older people reminiscing the 'quality' of the recollection does not necessarily reside in historical accuracy nor that the interviewee is representative of a wider sociological group, it is more in its communicative ability. So we need to consider how the role of narrativity might function in this process. There is the classic literary definition between story and narrative: the story being a chronological sequence of events; in contrast to the 'narrative discourse' which is the story as put into a narrative. So the story of my travel to Cambridge could be put into a narrative of my choice (depending where I decide to start and finish relating), or into a different narrative by my travelling companion (according to her choices and perspectives). So while I may decide to omit the coffee-buying and spilling event at Kings Cross Station from my travelogue type narrative, my companion may consider it to be central to her comic narrative.

So in terms of reminiscing we should be facilitating reminiscers' ability to produce the kind of narrative that they find satisfactory. And although our life stories do not become narratives until structured by a narrator, culture tends to impose a kind of narrative structure on life. Certainly life itself has a beginning and an end and while culture marks these passages ceremonially (christenings and funerals), it also imposes 'artificial' structures on the events in midlife. On the one hand we have personal events: marriages, graduations, birthdays (annual and 'significant') and bar mitzvahs.; on the other it may be our specific culture that deems events to be significant. These may be annual - determined by religious or national conventions ( $\mathrm{St}$ Patrick's Day, Independence Day, Diwali) or once-in-a-lifetime quasi-universal (the Millennium, town-twinning).

If we are in accord with Arnold van Gennep's scheme of things these rites de passage mark out ceremonially the changes of status and social identity imposed upon us according to the conventions of our own particular culture. "On the threshold" of these status changes (e.g. marriage or graduation), as part of the ceremonial proceedings the individual is usually given special clothing for the 
day - indeed the very moment to take a photo! At these events not only do we tend to use the camera to make a record, but over the last 150 years (in a curiously reflexive state of affairs) the act of photography itself has become a key player in these "life masterplots". That photography has attained its own special status in this regard, is marked by the fact that different cultural rules govern the ways photography is used on these occasions: permission may or may not be granted to take wedding photos in church or other locations; or different cultures have different attitudes to photographing the dead and/or placing the images on gravestones, etc.

Some maintain that it is the implied permanence of the photograph that has the potential to undermine 'true' memory. [19] [20] It has been suggested that the photograph, rather like a cuckoo's hatchling, implants itself in the mind of the reminiscer and takes over from the original the memory. As Brassaï puts it, in the context of Proust and photography, it derives from the "notion that persons and things can engender simulacra endowed with a life of their own and apt to replace those from which they issued" (p. 86)

Notwithstanding, in contrast to 'ordinary' objects (like Proust's madeleine), there is something special about the photograph in its ability to stimulate reminiscing (whether accurate or otherwise). Although the image represents one single framed moment it contains an implied narrative at the same time. Often it can be aspects of the photograph that are not necessarily the intention of the photographer. This not only depends upon our knowledge of states of affairs in the world, but also our familiarity with stories that exist within our culture may provide a wide range of potential stories which may lead the viewer, detective like, to look for details in the image which may provide evidence for their story expectations to be fulfilled. [21] However the lack of such details, or the presentation of contradictory evidence within the photograph, may simply serve to frustrate the viewer's quest for understanding and meaning. (This can be the deliberate goal of some artists, photographers or filmmakers, constituting an essential feature of their art). While it may be a human necessity to build still images into cause and effect narratives, so that it becomes difficult to refrain from attempting to situate the image in a narrative structure, we should also be aware that the memories evoked by photographs may not always be pleasant ones (Binney \& Chaplin 1991) [22].

\section{CONCLUSION}

Proust's À la recherche du temps perdu raises fundamental questions concerning the relationship between photography and memory that remain central to the processes of reminiscing aided by the 'new technologies' of today. While the purpose of photoelicitation, in the historical and anthropological sense, is to use the lens-based visual record to trigger memory to provide further information and/or social facts; with older people reminiscing, it is the interaction with the image and the act of recalling that is most significant. Whether the photograph accurately records how we remember things is not as important as its ability to provide stimulation and to encourage processes of interaction. In Liam Reilly's interview, it doesn't really matter if his account is true or not, but it does encourage the listener to speculate/contemplate the architectural phenomenon of the Drogheda Railway Viaduct in which the teller is displaying local pride as well as gaining personal mischievous enjoyment in recounting rather questionable narratives. As the old saying has it "Never let the facts get in the way of a good story."

\section{REFERENCES}

[1] Proust, Marcel 1969 Remembrance of Things Past (À la recherche du temps perdu). Translated by C.K. Scott Moncrieff. London: Chatto \& Windus.

[2] Epstein, R. 2004 "Consciousness, art, and the brain: Lessons from Marcel Proust" Consciousness and Cognition Vol. 13, Issue 2, 213-240

[3] Murphy, J.P. 2001 Proust's Art: Painting, Sculpture and Writing in À la Recherche Du Temps Perdu. New York: Peter Lang.

[4] Karpeles, E.2008 "Paintings in Proust: A Visual Companion to 'In Search of Lost Time"' London: Thames \& Hudson

[5] Sontag, S. 1977 On Photography New York: Farrar, Straus and Giroux

[6] Brassaï (Gyula Halász) 2001 Proust in the Power of Photography trans. Richard Howard. Chicago: University of Chicago Press. p. 56.

[7] Danius, S. 2002 The Senses of Modernism: Technology, Perception, and Aesthetics Cornell University Press

[8] Ryan, M-L 2001Narratvie as Virtual Reality: immersion and interactivity in literature and electronic media. Baltimore \& London: Johns Hopkins University Press. p. 121

[9] El Sur (The South) 1983 Victor Erice (Spain) Chloë Productions. $95 \mathrm{~min}$

[10] Foster, Roy F. 2001 The Irish Story: Telling Tales and Making It Up in Ireland London: Allen Lane/Penguin Press. p. 3 .

[11] Montfort, Nick 2007 "Narrative and Digital Media" in $D$. Herman (ed) The Cambridge Companion to Narrative. Cambridge: Cambridge University Press. pp. 172-186

[12] http://www.ist-nm2.org/

[13] Jordanova, L. 2006 History in practice $2^{\text {nd }}$ ed. London: Hodder. p. 92.

[14] Wright, T. 2008 Visual Impact: Culture and the Meaning of Images. Oxford: Berg. 141-156

[15] http://www.shapeshift.tv

[16] Nostalgia for the Central European Communist era is given the comedy drama treatment in Wolfgang Becker's GoodBye Lenin! (2003)

[17] Banks, M. 2001 Visual Methods in Social Research. London: Sage. p. 87

[18] Geffroy, Y. 1990 'Family photographs: a visual heritage' Visual Anthropology, 3 (4) 367-410.

[19] Strange, Deryn; Gerrie, Matthew P. \& Garry, Maryanne 2005 "A few seemingly harmless routes to a false memory" Cognitive Processing Volume 6, Number 4. 237-242.

[20] Wade, K. A., Garry, M., Read, J. D., \& Lindsay, D. S. (2002). "A picture is worth a thousand lies: Using false 
photographs to create false childhood memories".

Psychonomic Bulletin and Review, 9, 597-603.

[21] Schank's idea of the 'story skeleton'. Schank, Roger 1990 Tell me a Story: narrative and intelligence. Evanston: Northwestern University Press 147-88)
[22] Binney, Judith \& Chaplin, G. 1991 "Taking the photographs home: the recovery of Maori history" Visual Anthropology 4: 431-442. 